\title{
QUÍMICA GERAL EXPERIMENTAL: UMA NOVA ABORDAGEM DIDÁTICA
}

\author{
Geraldo Eduardo da Luz Júnior*, Samuel Anderson Alves de Sousa, Graziella Ciaramella Moita e José Machado \\ Moita Neto \\ Departamento de Química, Universidade Federal do Piauí, 64049-550 Teresina - PI
}

Recebido em 14/10/02; aceito em 5/8/03

\begin{abstract}
EXPERIMENTAL GENERAL CHEMISTRY: A NEW TEACHING APPROACH. This essay describes a new didactic approach, in according with the national curriculum guidelines for chemistry undergraduate courses in Brazil, employed during the onesemester course "Experimental General Chemistry" for chemistry undergraduate students at the Federal University of Piauí. The new approach has positively helped student's training by improving their reading skills and their understanding of scientific reports, by developing the use of electronic tools to search and to recover the required knowledge for their learning activities, and by improving their skills of understanding published texts and dealing with digital sources. At the same time the students are strongly stimulated to enter the research program for undergraduate students available at the University.
\end{abstract}

Keywords: experimental courses; national curriculum guidelines; scientific initiation program.

\section{INTRODUÇÃO}

Embora a ciência tenha presença garantida em nossa sociedade pelos frutos tecnológicos colocados à disposição do cidadão, a prática científica, em seu dia-a-dia, é ainda grandemente desconhecida. Isto leva à idealização sobre o fazer ciência ou a críticas improcedentes sobre a pesquisa. As atividades laboratoriais existentes nos ensinos médio e superior revestem-se de artificialismos que dificultam o aprendizado e o despertar científico dos alunos. Por outro lado, o emprego de materiais utilizados no cotidiano dos alunos, em aulas práticas, aumenta grandemente o interesse dos mesmos, tanto no trabalho experimental, quanto no entendimento dos fenômenos envolvidos.

A Química é uma das ciências que sofreu maior impacto, tanto pela mudança de paradigma teórico no início do século passado, com o advento da mecânica quântica, quanto pelo notório crescimento na capacidade dos computadores. A Química é hoje uma ciência central no entendimento da revolução científica em andamento, tanto por suas interfaces com a Biologia (p. ex.: Produtos Naturais, Bioquímica, etc), Física (p. ex.: Físico-Química), Engenharia (p. ex.: Materiais), quanto por suas aplicações em Agronomia, Ciência dos Alimentos, Farmacologia, etc.

Dentre as questões que podem ser colocadas sobre o assunto, a que adquire mais urgência é como preparar o cidadão para o domínio destes novos saberes, que crescem de maneira cada vez mais veloz. Ou ainda, até que ponto o cidadão comum deve compreender a atividade científica para ter uma visão lúcida e equilibrada sobre o seu desenrolar. Estas mesmas questões devem ser colocadas com maior intensidade para os alunos dos cursos de graduação em Química, pois serão eles os gestores desses saberes diante da sociedade.

A configuração do novo cenário da pesquisa científica na área de Química vem se consolidando, de modo que é possível propor um conjunto de atividades teórico-práticas que possam preparar o cidadão a entender com maior profundidade o significado da pesquisa e o seu modo de fazê-la. Este programa deve partir da fundamentação química básica e avançar até a utilização de equipamentos

*e-mail: geraldo@ufpi.br sofisticados. Vários aspectos de importância para a formação acadêmica do estudante de Química incluem noções de estatística, uso de softwares gráficos, coleta de informações de qualidade em fontes bibliográficas eletrônicas e utilização de programas computacionais de aplicação específica na Química. Além dos pontos mencionados anteriormente, é necessário o desenvolvimento de um projeto de pesquisa individual, em que seja possível vivenciar todas as etapas aprendidas anteriormente e a conseqüente elaboração de comunicação científica, seja na forma de relatório, artigo ou trabalho em congresso científico. Um conjunto de atividades assim desenvolvidas estaria de acordo com as Diretrizes Curriculares Nacionais para os Cursos de Química ${ }^{1}$.

\section{PROPOSTA}

Dentro do espírito anteriormente referendado, preparamos o curso de Química Geral Experimental, a primeira disciplina experimental cursada pelos graduandos em Química (Bacharelado e Licenciatura) da Universidade Federal do Piauí. Esta disciplina consta de 15 aulas práticas perfazendo o total de $30 \mathrm{~h}$ e é complementada teoricamente pela disciplina Química Geral I de 60 h.

Essas disciplinas são independentes da Química Geral II, que trata especificamente dos equilíbrios químicos de maneira aprofundada. Neste trabalho apresentamos o modo como a disciplina Química Geral Experimental vem sendo ministrada na UFPI, as práticas aplicadas, os recursos didáticos utilizados e os resultados observados em duas turmas dessa disciplina.

A partir das Diretrizes Curriculares Nacionais para os Cursos de Química, elaboramos diretrizes específicas para o curso Química Geral Experimental da Universidade Federal do Piauí, as quais estão apresentadas na Tabela 1.

A ementa registrada para esse curso é a seguinte: normas de segurança, técnicas elementares de laboratório, construção de gráficos, soluções (unidades de concentração), velocidade de reações e ligações químicas.

Os objetivos propostos para essa disciplina visam levar os alunos a: conhecer normas de segurança de um laboratório químico; manusear adequadamente vários utensílios do laboratório; aprender as técnicas elementares de laboratório; confeccionar e interpretar 
Tabela 1. Diretrizes do curso de Química Geral Experimental da Universidade Federal do Piauí

\begin{tabular}{lll}
\hline $\begin{array}{l}\text { Com relação à busca de informação, à comunicação e } \\
\text { expressão }\end{array}$ & Com relação à formação pessoal & $\begin{array}{l}\text { Com relação à compreensão da } \\
\text { Química }\end{array}$
\end{tabular}

Saber identificar e fazer busca nas fontes de informações relevantes para a Química, inclusive as disponíveis nas modalidades eletrônica e remota, que possibilitam a contínua atualização técnica e científica.

Ler, compreender e interpretar os textos científicotecnológicos em idioma pátrio e inglês.

Saber interpretar e utilizar as diferentes formas de representação (tabelas, gráficos, símbolos, expressões, etc), assim como saber escrever e avaliar criticamente os materiais didáticos, como livros, apostilas, "kits", modelos, programas computacionais e materiais alternativos.

Demonstrar bom relacionamento interpessoal e saber redigir corretamente os projetos e resultados de pesquisa (textos, relatórios, pareceres, laudos, pôsteres, "internet", etc) em idioma pátrio.
Possuir domínio das técnicas básicas de utilização de laboratórios, bem como dos procedimentos necessários de primeiros socorros, nos casos dos acidentes mais comuns em laboratórios de Química.

Saber trabalhar em equipe e ter boa compreensão das diversas etapas que compõem uma pesquisa.

Ter interesse no auto-aperfeiçoamento contínuo, curiosidade e capacidade para estudos extracurriculares individuais ou em grupo, espírito investigativo, criatividade e iniciativa na busca de soluções para questões individuais e coletivas relacionadas à Química.
Compreender conceitos, leis e princípios da Química.

Acompanhar e compreender os avanços científico-tecnológicos. gráficos; preparar soluções e expressar sua concentração em diferentes unidades; identificar as evidências de ocorrências de uma reação química; identificar os fatores que afetam a velocidade de uma reação química.

Diante das diretrizes propostas para a disciplina e do seu plano de ensino as aulas práticas foram planejadas, sendo temas, objetivos e tarefas apresentados na Tabela 2.

Para alcançar as diretrizes apresentadas na Tabela 1 e os objetivos da Tabela 2, sem abrir mão de cobrir toda a ementa, o curso apresenta as seguintes características: página na "internet" (Quadro 1) que contém todas as informações relevantes do curso, tais como plano de curso, um guia do estudante de Química, sugestões sobre como se escrever um relatório (Quadro 2), os critérios de correção dos relatórios (Quadro 3), as diretrizes do curso (Tabela 1), o roteiro de todas as práticas (conforme exemplo apresentado no Quadro 4) e vários "links" de interesse dos alunos da disciplina. Na aula anterior à execução da prática são formados grupos de três alunos e indicada a prática a ser realizada na aula seguinte. Tais grupos têm sua composição variada a cada prática a fim de promover uma maior integração entre os alunos.

O roteiro da prática é obtido consultando-se a página da disciplina na "internet". Os roteiros, conforme exemplo apresentado no Quadro 4, constam de título, objetivos, tarefas a serem realizadas, tarefas pré-laboratoriais, sugestões bibliográficas e "sites" relacionados aos respectivos temas das práticas, mas não apresentam um detalhamento do procedimento a ser adotado na aula, sendo a prática detalhada somente durante a aula.

No dia da realização da prática, os alunos, com o roteiro em mãos, são incentivados a manifestarem-se durante as aulas. Inicialmente são abordados os objetivos. O ministrante intervém apenas para provocar a participação de todos e esclarecer as dúvidas oriundas das intervenções. Em seguida, o professor apresenta no quadro a

QUADRO 1. Página inicial na “internet” da disciplina Química Geral Experimental (http://www.ufpi.br/quimica/disciplinas/QGE.htm)

Química Geral Experimental/Profa. Dra. Graziella Ciaramella Moita

\begin{tabular}{|c|c|c|c|c|}
\hline \multicolumn{2}{|c|}{ Plano de Curso } & Resolução 43/95 & & iretrizes \\
\hline \multirow{2}{*}{\multicolumn{2}{|c|}{$\begin{array}{l}\text { Guia do Estudante de Química } \\
\text { Conhecendo o aluno }\end{array}$}} & Relatório & \multirow{2}{*}{\multicolumn{2}{|c|}{$\begin{array}{c}\text { Pontuação } \\
\text { Caderno de laboratório }\end{array}$}} \\
\hline & & Laboratório & & \\
\hline \multicolumn{5}{|c|}{ Práticas } \\
\hline \multirow[t]{2}{*}{ Material de laboratório } & Leitura orientada & \multicolumn{2}{|c|}{ Gramatura do papel } & Densidade de líquidos \\
\hline & Preparo de solução & \multicolumn{2}{|c|}{ Titulação } & Sal de fruta \\
\hline \multicolumn{5}{|c|}{ "links" } \\
\hline Depto de Química & Disciplinas do DQ & Mestrado em Química & UFPI & $\mathrm{CCN}$ \\
\hline Scielo & Qmcweb & Allchemy & ChemFinder & Chemkeys \\
\hline Origin & Nobel de Química & Sistema Internacional & $\mathrm{ABQ}$ & SBQ \\
\hline Pesquisa no JCE & Web of Science & SBQ-PI & Moderna OnLine & SBPC \\
\hline
\end{tabular}


Tabela 2. Temas, objetivos e tarefas das aulas práticas

\begin{tabular}{lll}
\hline Título da prática & Objetivos & Tarefas \\
\hline Material de laboratório & $\begin{array}{l}\text { Conhecer os principais utensílios de um } \\
\text { laboratório de Química e suas aplica- } \\
\text { ções. }\end{array}$ & $\begin{array}{l}\text { Identificar as principais vidrarias e utensílios em um laboratório } \\
\text { químico e conhecer suas aplicações. }\end{array}$ \\
\hline Leitura orientada & $\begin{array}{l}\text { Aprender a pesquisar artigos científicos } \\
\text { na "internet", traduzir o "abstract" de } \\
\text { um artigo e a solicitar separata de artigo } \\
\text { científico. }\end{array}$ & $\begin{array}{l}\text { Traduzir o "abstract" de artigo do Journal of Chemical Educa- } \\
\text { tion obtido na "internet"; obter artigos sobre práticas de } \\
\text { laboratório que existam na Biblioteca; solicitar separata de artigos } \\
\text { científicos de interesse. }\end{array}$ \\
\hline Gramatura do papel & $\begin{array}{l}\text { Determinar a razão entre a massa e a área } \\
\text { de uma folha de papel; realizar cálculos } \\
\text { para determinação de média e desvio } \\
\text { padrão. }\end{array}$ & $\begin{array}{l}\text { Fazer medidas de área e massa identificando em ambos os casos } \\
\text { a precisão dos instrumentos utilizados; obter a gramatura do papel } \\
\text { e expressá-la através de parâmetros estatísticos apropriados (média } \\
\text { e desvio padrão); comparar o valor obtido com o valor de } \\
\text { gramatura indicado para o papel utilizado (erro); obter a área e o } \\
\text { raio de um círculo através de medidas de massa. }\end{array}$ \\
\hline
\end{tabular}

Densidade de líquidos

\begin{abstract}
Determinar a massa e o volume de líquidos e obter a densidade desses através de regressão linear simples, utilizando o programa estatístico computacional Origin.
\end{abstract}

Fazer medidas de volume e massa identificando em ambos os casos a precisão dos instrumentos utilizados; obter a densidade da água através de regressão linear simples; comparar o valor obtido para densidade da água com o valor existente na literatura; obter a densidade de álcool comercial e associá-lo com o teor de álcool indicado no frasco.
Preparo e diluição de uma solução
Realizar os procedimentos de preparo de soluções sólido-líquido; determinar a concentração de soluções; conhecer as diversas formas de se expressar a concentração de uma solução; realizar procedimentos de transferência quantitativa de soluções.
Preparar soluções de sulfato de cobre II penta-hidratado em um balão volumétrico de $250 \mathrm{~mL}$; transferir quantitativamente uma solução usando pipeta; calcular a concentração das soluções preparadas e expressá-las de várias formas.
Titulação

Determinar a concentração de $\mathrm{HCl}$ por volumetria de neutralização, utilizando indicador ácido-base.
Fazer medidas de volume usando bureta e pipeta; detectar o ponto final da titulação através de indicador visual; fazer os cálculos em análise volumétrica; determinar a concentração de ácido por reação com base.
Sal de frutas
Estudar as reações químicas da dissolução do sal de fruta em água.
Conferir o peso líquido da amostra de sal de fruta; analisar as reações químicas envolvidas na dissolução do sal de fruta em água; discutir os aspectos cinéticos envolvidos na reação; discutir as reações químicas da solução formada no organismo humano. maneira como será conduzida a prática, mas sem indicar muitos detalhes; estes serão fornecidos à medida que forem surgindo as dúvidas, ou os alunos forem percebendo seus próprios erros. Como normalmente os experimentos são realizados em pelo menos duas etapas, após a realização da primeira, os erros cometidos são discutidos com toda a turma e as dúvidas são esclarecidas. Em seguida, os alunos realizam a segunda etapa, tendo consciência dos erros que devem ser evitados.

Os alunos são orientados a pesquisar e estudar previamente o assunto a ser abordado na aula prática seguinte, com o objetivo de facilitar a compreensão do conteúdo abordado nas referidas aulas e auxiliar na elaboração do relatório.

Quinze dias após a realização da prática, cada grupo apresenta um relatório, redigido de acordo com o roteiro (Quadro 2) que foi discutido e esclarecido no início do período letivo. O professor anota os erros e pontos falhos no conteúdo e na forma em cada relatório durante sua correção, que é realizada de acordo com critérios pré- definidos (Quadro 3). Na aula em que os relatórios são devolvidos aos alunos, todos os erros são discutidos exaustivamente com a turma, para que sejam evitados nos relatórios seguintes.

Outras atividades realizadas em sala de aula são a leitura orientada de um "abstract" do Journal of Chemical Education e a solicitação de uma separata do texto lido. No tocante aos materiais de apoio, tais como sugestões bibliográficas, sempre presentes, são indicados "sites" no roteiro de cada prática, que contêm informações relacionadas aos assuntos de cada uma das aulas, além dos "sites" de busca. Os alunos são avaliados pelos seus desempenhos durante as aulas e pela elaboração dos relatórios.

Quando da formação do primeiro grupo, no início do período, os alunos são notificados de que este grupo, além de realizar a primeira prática, deverá escolher uma experiência, que não necessite de nenhum material da Universidade para sua execução; apresentar um roteiro dessa prática até uma data determinada e, no final do curso, executá-la e explicá-la devidamente. 


\section{RESULTADOS}

A mudança periódica na composição dos grupos de trabalho mostrou-se útil para alunos e professor, pois permitiu uma integração maior da turma, que está iniciando o curso de Química. Evitou os vícios na realização dos relatórios e permitiu que o professor identificasse os alunos que efetivamente participavam da redação dos textos.

A página do curso na "internet", juntamente com a não entrega dos roteiros das práticas aos alunos, fez com que esses utilizassem a "internet" continuamente, habilitando-os a utilizarem, de maneira correta, esse importante recurso, além de constituir-se um mural eletrônico do professor.

O roteiro simplificado das práticas e a breve explicação dos roteiros por parte do professor levou a maior parte dos alunos a participarem efetivamente das aulas expondo as dúvidas e evitou que eles apenas copiassem os procedimentos quando fossem escrever os relatórios, o que os ajudou a amadurecerem no modo de descreverem a prática realizada. Além disso, possibilitou o aprimoramento do espírito crítico dos alunos que, por não saberem detalhes da manipulação dos equipamentos e reagentes, percebiam por eles mesmos as fontes de erros cometidos nas práticas, evitando-os posteriormente. Certamente o conhecimento adquirido dessa forma é melhor assimilado do que a simples informação repassada pelo professor.

O estudo prévio dos conteúdos referentes às práticas por parte dos alunos, além de facilitar a compreensão, aumentou a curiosidade sobre as práticas.

As orientações contidas no "site" do curso sobre os relatórios, assim como as discussões gerenciadas pelo professor, após correção daqueles, conduziu os alunos a um crescente desempenho no tocante à elaboração dos mesmos. O roteiro para execução dos relatórios e a tabela de pontos (Quadro 3), que é utilizada na correção, possibilitou que o aluno identificasse a forma como seria avaliado o relatório e, o que é mais importante para sua formação profissional, ele percebeu que sua capacidade de relacionar a prática com a teoria, bem como apurar seu espírito crítico, são os pontos principais, já que a pontuação relativa aos resultados, à discussão e à conclusão correspondem a $40 \%$ da nota do relatório.

O primeiro relatório, normalmente, apresentou notas baixas $(4,0$ - 6,0), porém houve uma grande evolução durante o período. No último relatório as notas variaram de 6,0 a 10,0, sendo que mais de $50 \%$ dos grupos obtiveram notas acima de 8,0. Dessa forma, cerca de $95 \%$ dos $81 \%$ dos alunos que não desistiram da disciplina foram aprovados por média.

O progresso durante o curso possibilitou a escolha e o preparo de práticas pelos próprios alunos, as quais foram apresentadas com utilização de materiais simples, do cotidiano deles.

O incentivo à consulta a "sites" na "internet", à leitura de textos em inglês, à utilização de programas gráficos e de estatística, à participação efetiva no preparo (pré-laboratório) e execuções de práticas, ao aprofundamento da teoria e à redação de relatórios, além de desenvolver o espírito crítico dos alunos, preparou-os para as demais disciplinas experimentais e também teóricas do curso de Química.

Em conversa com os alunos, no último dia de aula, sobre os pontos positivos e os negativos da disciplina, a maioria se manifestou positivamente, como pode ser visto no depoimento de um dos alunos apresentado no Quadro 5. Eles perceberam a evolução que tiveram, não apenas através das notas, mas também por sentirem uma maior facilidade no entendimento das práticas e na elaboração dos relatórios.

Desde o início da disciplina há uma abordagem sobre a Iniciação Científica, particularmente no tocante à aplicação dos conhecimentos teórico-práticos por parte dos alunos. O resultado de tal abordagem, aliada à mudança de enfoque da disciplina, pode ser notado nitidamente nas turmas avaliadas. Atualmente, cerca de $45 \%$ dos alunos dessas turmas são bolsistas dos programas de Iniciação Científica oferecidos pela UFPI, além de muitos outros trabalharem como pesquisadores voluntários.

\section{CONCLUSÃO}

A mudança radical de enfoque da primeira disciplina experimental do Curso de Química da Universidade Federal do Piauí provocou um despertar da consciência crítica dos alunos e os ajudou a colocarem-se, desde o primeiro momento, na posição de alunos - pesquisadores, preparando-os para os desafios sempre novos da Química. Além disso, estimulou-os a ingressarem em um dos programas de Iniciação Científica oferecidos pela referida instituição de ensino.

\section{REFERÊNCIA}

1. Diretrizes Curriculares Nacionais para os Cursos de Química (Parecer $N^{\circ}$ : CNE/CES 1.303/2001, aprovado em: 06/11/2001).

\section{QUADRO 2. Constituição de um relatório}

Uma composição qualquer deve conter sempre as seguintes partes: INTRODUÇão, DESENVOLVIMENTO e CONCLUSÃo. Tratando-se de um relatório de uma disciplina experimental aconselhamos a seguinte seqüência:

- TÍTULO: Frase sucinta que indica o principal objetivo da experiência.

- RESUMO: Texto de no máximo cinco linhas, descrevendo tudo o que foi feito, inclusive os resultados alcançados.

- INTRODUÇÃO: Descrição de toda teoria necessária ao entendimento da prática e da discussão dos resultados. Particularmente no caso de Química Analítica, a introdução deve conter a teoria do método analítico, das fontes e efeitos dos erros, descrição da amostra. Deve ser uma síntese própria dos vários livros consultados. Evite rodeios. O objetivo do trabalho deve aparecer no último parágrafo da introdução, podendo ficar separado desta para maior destaque.

- PARTE EXPERIMENTAL: Descrever o procedimento experimental, ressaltando os principais materiais e equipamentos utilizados. Preferencialmente dividir em dois subitens: Materiais e Reagente, e Procedimento Experimental.

- RESULTADOS: Consiste na apresentação de todos os dados colhidos em laboratório ou dos calculados decorrentes dos dados. Devem ser apresentados na forma de tabelas, gráficos, etc, de modo a comunicar melhor a mensagem.

- DISCUSSÃO: Discutir os dados obtidos à luz da teoria exposta e comparar com os dados da literatura. Analisar as fontes de erros, a exatidão e precisão da análise e, sempre que possível, comparar com a literatura ou com informações sobre a amostra. A discussão é a parte do relatório que exige maior maturidade do aluno.

Obs.: Estes dois itens podem ser agrupados em um único item: RESULTADOS E DISCUSSÃO.

- CONCLUSÃO: Síntese pessoal sobre as conclusões alcançadas com o seu trabalho. Enumere os resultados mais significativos do trabalho. Não deve apresentar nenhuma conclusão que não seja fruto da discussão.

- REFERÊNCIAS: Livros e artigos usados para escrever o relatório. Devem ser indicados cada vez que forem utilizados. 
QUADRO 3. Tabela de Pontuação do relatório

\begin{tabular}{|c|c|c|}
\hline Seção & Aspectos Avaliados & Pontuação \\
\hline Apresentação & Estética na apresentação do relatório. & 0,5 \\
\hline Capa & Com todas as informações importantes. & 0,5 \\
\hline Resumo & Conforme explicitado no roteiro de relatório. & 1,0 \\
\hline Introdução & $\begin{array}{l}\text { Fundamentação teórica de todos os assuntos envolvidos na prática tendo como } \\
\text { referência a bibliografia consultada. }\end{array}$ & 1,5 \\
\hline Objetivo & Expresso de forma clara. & 0,5 \\
\hline \multirow[t]{2}{*}{ Parte Experimental } & $\begin{array}{l}\text { Materiais e Reagentes: Lista completa com as respectivas especificações dos materiais } \\
\text { (marca, modelo, etc.) e reagentes (marca, grau de pureza, etc.) utilizados na prática. }\end{array}$ & 0,5 \\
\hline & $\begin{array}{l}\text { Procedimento: Texto claro e objetivo do trabalho desenvolvido, de modo que possa ser } \\
\text { reproduzido por outra pessoa. }\end{array}$ & 1,0 \\
\hline Resultados & $\begin{array}{l}\text { Apresentação de texto explicativo introdutório precedendo a apresentação dos resultados } \\
\text { experimentais que, quando pertinentes, devem ser apresentados na forma de tabelas e gráficos. }\end{array}$ & 1,0 \\
\hline Discussão & Conforme explicitado no roteiro de relatório. & 2,0 \\
\hline Conclusão & Conforme explicitado no roteiro de relatório. & 1,0 \\
\hline Referências & Conforme explicitado no roteiro de relatório. & 0,5 \\
\hline
\end{tabular}

QUADRO 4. Exemplo do roteiro das práticas: determinação da densidade de líquidos

Objetivo: Determinar a razão entre a massa e o volume de líquidos e utilizar recursos eletrônicos para obter a densidade da água através de regressão linear simples.

Tarefas:

1. Fazer medidas de volume e massa identificando em ambos os casos a precisão dos instrumentos utilizados;

2. Obter a densidade da água através de regressão linear simples;

3. Comparar o valor obtido para densidade da água com o valor existente na literatura;

4. Obter a densidade do álcool comercial e associá-la com o teor de álcool indicado no frasco.

Observação: Pesquise as densidades do álcool etílico e da água no Handbook.

Material de apoio (internet):

Unidades Legais de Medir; Densidade de líquidos; Densímetros; Álcool hidratado (propaganda); Garrafas de álcool; Álcool Copersucar; Balança Analítica; INMETRO.

Sugestão Bibliográfica:

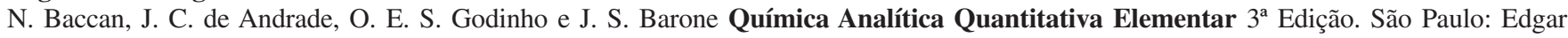
Blucher; Campinas: Universidade Estadual de Campinas, 2001.

Exemplo de gráfico: Densidade do álcool

\section{QUADRO 5}

Depoimento do aluno S. A. A. de Sousa após conversa com seus colegas da disciplina Química Geral Experimental ministrada no primeiro período de 2001 .

A experiência vivida na disciplina Química Geral Experimental I, no primeiro período de 2001, pelos alunos que hoje fazem parte da iniciação científica foi extremamente proveitosa devido aos seguintes fatores:

1- O aprendizado de técnicas de pesagens e manuseio das diversas vidrarias do laboratório foi mais tarde essencial para eles, pois foram obrigados a pôr em prática o que tinham aprendido no decorrer do treinamento da iniciação científica, e como a disciplina havia fornecido o primeiro contato com tais técnicas o treinamento foi de certa forma facilitado;

2- O contato com o computador seja no acesso à "internet" ("links" de busca), ou na utilização de softwares aplicados, ensinou-os como utilizar estas ferramentas. O modo de fazer e refinar uma pesquisa na "internet" (AND e OR) e também o uso do Origin para tratamento de dados são aprendizados que, com certeza, acompanharão todos os alunos até o final dos seus cursos, ou até mesmo numa possível pósgraduação;

3- A exigência do caderno de laboratório pode parecer a primeira vista uma coisa banal, porém desta forma foi ensinado aos alunos como se organizar dentro do laboratório e também a não perder resultados por falta de anotação;

4- As normas de segurança e conduta aprendidas dentro do laboratório são ainda praticadas e com certeza nunca serão abandonadas;

5- Talvez o aspecto mais importante resida no fato de os alunos terem evoluído na confecção dos relatórios. Isto foi notório durante a disciplina, onde os primeiros relatórios apresentaram notas baixas enquanto que nos últimos houve uma melhora significativa no texto (e conseqüentemente na nota). A importância deste fato é reforçada lembrando que no decorrer do curso de química são muitas as disciplinas que exigem relatórios e, além disso, um aluno de iniciação científica precisa saber elaborar um texto científico para possíveis publicações de resultados de trabalhos de pesquisa.

Enfim, a disciplina Química Geral Experimental foi a pedra fundamental para os alunos que dela participaram e a partir dela se tornaram alunos de iniciação científica. 